\title{
DEUTSCHE DOME
}





\title{
Dî $\mathfrak{B e f t f a ̈ ́ l i f i t h e n ~ S o m e ~}$ Paderborn Soeft $\mathfrak{D} \mathfrak{z} \mathfrak{a} \mathfrak{b} \mathfrak{u} \mathfrak{a}$ $\mathfrak{M i n d e n} \mathfrak{M} \mathfrak{u} \mathfrak{n} \mathfrak{i t e r}$
}

\author{
Aufgenommen von \\ WALTER HEGE \\ bejd)rieben von \\ WERNER BURMEISTER
}

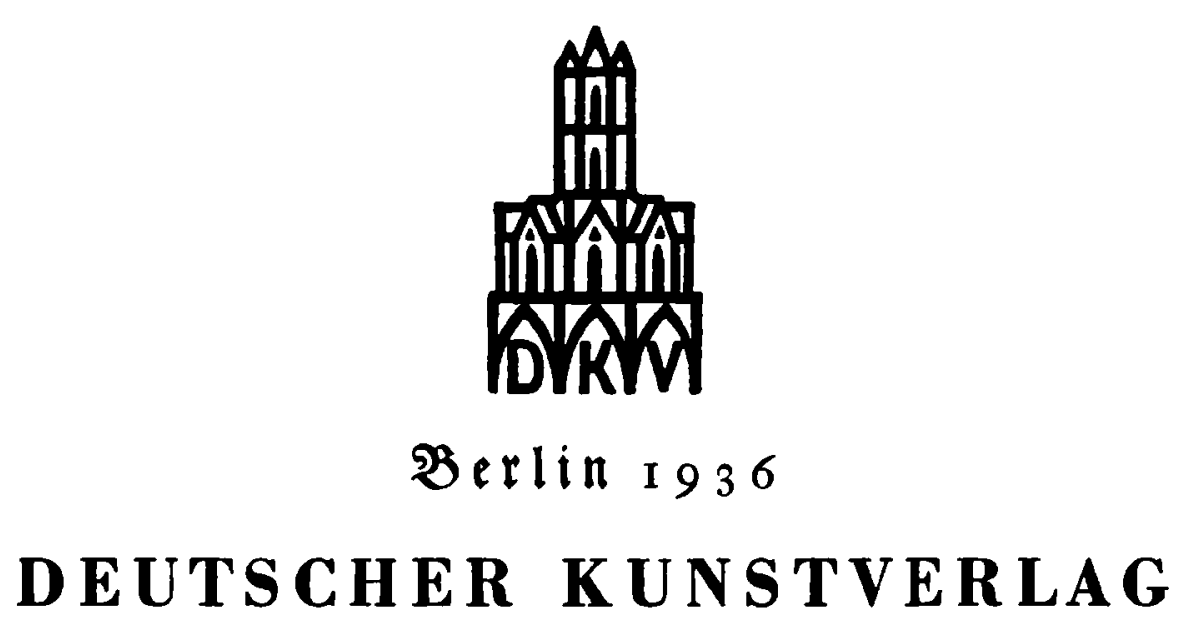

